\title{
Ultrastructure of mouse intestinal mucosa and changes observed after long term anthraquinone administration
}

\author{
P DUFOUR AND P GENDRE
}

\begin{abstract}
From the Department of Pharmacology, University of Bordeaux II, School of Pharmacy, France, and Department of Electron Microscopy, University of Bordeaux I, France
\end{abstract}

SUMMARY In an attempt to study the relative toxicity of anthraquinonic laxatives on intestinal mucosa, we compared in mice the effects of fruit pulp containing sennosides A and B with those of a free anthraquinone, 1-8 dihydroxyanthraquinone. Observations have been made with transmission electron microscopy (EM) after 16 weeks of treatment with the two drugs. Although the doses used in this study were equipotent in terms of laxative activity, no damage to the intestinal tissue was observed with the sennosides. A number of changes, however, were detected in intestinal nervous tissues of all the animals treated with 1-8 dihydroxyanthraquinone, mainly in the form of vacuolisation of the axons, formation of lysosomal structures and in some cases appearances of fibrillar degeneration.

A large number of people habitually take laxatives over long periods of time. A small group of patients are serious abusers of laxatives, for complicated psychological reasons: they usually conceal the habit and may be difficult to diagnose. Laxatives of the anthraquinone group are presumed to be severe cell poisons following prolonged intake. Histological and ultrastructural studies in patients with chronic laxative misuse have indicated damage of the myenteric plexus and of the colonic epithelium. ${ }^{12}$

Damage of the myenteric plexus was reported by Smith $^{1}$ in the mouse after intraperitoneal, or oral administration of syrup of senna. Unfortunately neither the quantity of syrup used, nor the strain of the animals were stated. Nevertheless, the mouse seems to be a good animal model for the study of laxative toxicity.

In previous experiments on mice (Swiss strain) we were unable to find any histological, or ultrastructural changes in the jejunal and colonic mucosa after oral administration of a standardised senna powder for 11 weeks at a dose equivalent to sennosides A and B $10 \mathrm{mg} / \mathrm{kg}$ - approximately 50 -fold the therapeutic dose in man. ${ }^{3}$ Light microscope examination showed no difference between untreated and treated animals: autonomic nerve fibres and interstitial cells were normal in the two groups. Electron microscope (EM) examination

Address for correspondence: Dr Philippe Dufour, Faculté de Pharmacie, 3 Place de la Victoire, 33000 Bordeaux, France.

Received for publication 24 February 1984 showed no ultrastructural differences: enterocytes and nerve structures had the same aspect in control and treated animals, both in the jejunum and in the colon.

The differences in our results from those of others could be explained by the fact that syrup used by Smith may have contained free anthraquinones produced by hydrolysis of glycosides. Instability of syrup of senna has been pointed out by some authors. ${ }^{45}$ Unlike glycosides, free anthraquinones are absorbed from intestinal mucosa. ${ }^{6}$ They are then concentrated in the bile as conjugates and split into free anthraquinones by intestinal bacterial enzymes. ${ }^{7}$ High concentrations of anthraquinones in the intestinal wall associated with a possible direct effect on the jejunum may be more toxic to intestinal cells than glycosides. This difference in the metabolic pathway between glycosides and free anthraquinones has been reported by several groups $^{8-12}$ and it has been suggested that the enhanced absorption of anthraquinones makes them much more toxic than glycosides. ${ }^{13}$

In order to test this hypothesis, we have compared in the mouse the effects of sennosides A and B with those of a synthetic aglycone at doses producing the same laxative activity.

\section{Methods}

ANIMALS

Experiments were performed on 30 NMRI strain 
male mice (EVIC CEBA breeding, France), weighing $24 \mathrm{~g}$ at the start of the study. Before and during the experiments the animals were kept in polypropylene cages, except during laxative activity measurements (see below). Food (UAR. Ref. 104) and water were given ad libitum.

\section{TREATMENT}

Fruit pulp containing $0 \cdot 17 \%$ sennosides $A$ and $B^{*}$ or 1-8 dihydroxyanthraquinone $\dagger$ was used for dosing the animals. The 30 animals were divided into three groups of 10 and received by gastric tube $0.3 \mathrm{ml} / 20 \mathrm{~g}$ body weight/day for 16 weeks either: arabic gum suspension $2.5 \%$ (Group I); or fruit pulp suspension in arabic gum $2.5 \%$ containing sennosides 0.626 $\mathrm{mg} / \mathrm{ml}(0.187 \mathrm{mg} / 20 \mathrm{~g}$ ) (Group II); or Danthron suspension in arabic gum $2.5 \%$ containing $1-8$ dihydroxyanthraquinone $16.7 \mathrm{mg} / \mathrm{ml}(5.01 \mathrm{mg} / 20 \mathrm{~g})$ (Group III).

\section{EXPERIMENTAL PROCEDURES}

General appearance, behaviour and weight of the animals were recorded daily.

\section{Measurements of laxative activity}

Faecal output was measured daily during the first four weeks of the study. During six hours after dosing the animals were placed in separate cages fitted with a wire-mesh floor in order to recover faeces separately. Laxative activity was measured by Lou and Fairbairn method ${ }^{22}$ as modified by Brittain and d'Arcy, ${ }^{23}$ by counting the number of stools of soft consistency. Laxative activity was expressed as the percentage of soft stools relative to the total number of stools after six hours. Results are expressed as mean $\pm \mathrm{SD}$. Unpaired $t$ test was used to determine the statistical significance between treated and control groups.

\section{EM examination}

The animals were killed after 16 weeks of treatment by decapitation and tissue specimens from each animal from the jejunum and the colon were taken for examination under EM. Jejunal tissue was sampled from a zone located at $20 \mathrm{~cm}$ distal to the pylorus. Colonic tissue consisted of the part of ascending colon distal to the caecum.

The specimens were fixed in glutaraldehyde $3 \%$ solution in $0.1 \mathrm{M}$ cacodylate buffer, then rinsed in a solution consisting of 1 volume cacodylate buffer and three volumes of bi-distilled water. The samples were postfixed in $1 \%$ osmium tetroxide, dehydrated in alcohol and embedded in epoxy resin. Ultra-thin sections from three blocks from each animal were

\footnotetext{
* Tamarine, Laboratoires du Docteur FURT SA, France.
}

† Danthron, Merck. cut on LKB microtome and stained with uranyl acetate and lead citrate. Five grids (with four or five ultra-thin sections on each one) from each block were examined in a RCA EMV $3 \mathrm{G}$ electron microscope. The examinations were performed by the same observer $(\mathrm{Ph} \mathrm{G})$, who was unaware of the experimental conditions.

\section{Results}

No animals died during the study. The general appearance, behaviour, and weight gain were normal in the three groups during the 16 weeks of the study. At the end of the study, the weights of the animals were respectively $48.1 \pm 4.7 \mathrm{~g}, 46.9 \pm 2.8 \mathrm{~g}$, and $47 \cdot 5 \pm 3.2 \mathrm{~g}$ (mean $\pm \mathrm{SD})$ in groups I, II and III.

\section{LAXATIVE ACTIVITY}

The proportion of soft stools was significantly higher $(p<0.001)$ in the animals given laxatives, but there was no significant difference $(p>0.05)$ between the two treated groups. The (soft stools/total stools) $\times$ 100 ratios were $5 \pm 3$ for group I, $31 \cdot 7 \pm 8.7$ for group II and $35 \cdot 7 \pm 9 \cdot 8$ for group III.

\section{EM RESULTS \\ Ultrastructure of jejunum and colon in controls \\ (group I) \\ Jejunal villi}

The enterocytes were columnar in form with their typical apical microvilli. Mucus cells, argentaffin cells, Paneth cells, components of the lamina propria and muscle layers revealed their well known and usually described structures. The nerve elements were myelin free fibres with abundant neurotubules and neurofilaments (Figs 1 and 2).

\section{Colon}

The ultrastructure of the crypts of Lieberkühn, of the lamina propria and of the muscle layers were similar to those generally observed. Innervation of the tissue with myelin free fibres was again observed.

\section{Changes observed in treated animals (groups II and III)}

The only differences detected in intestinal ultrastructure between controls and treated animals were in the intrinsic nervous tissue. In treated animals, there was no observable increase in smooth reticulum, or in the number of lysosomes, and no abnormalities in the microvilli of the brush border. Desquamation, a normal phenomenon in renewal cycle, was not increased in the treated animals. The mucus cells were abundant and exhibited intensive 

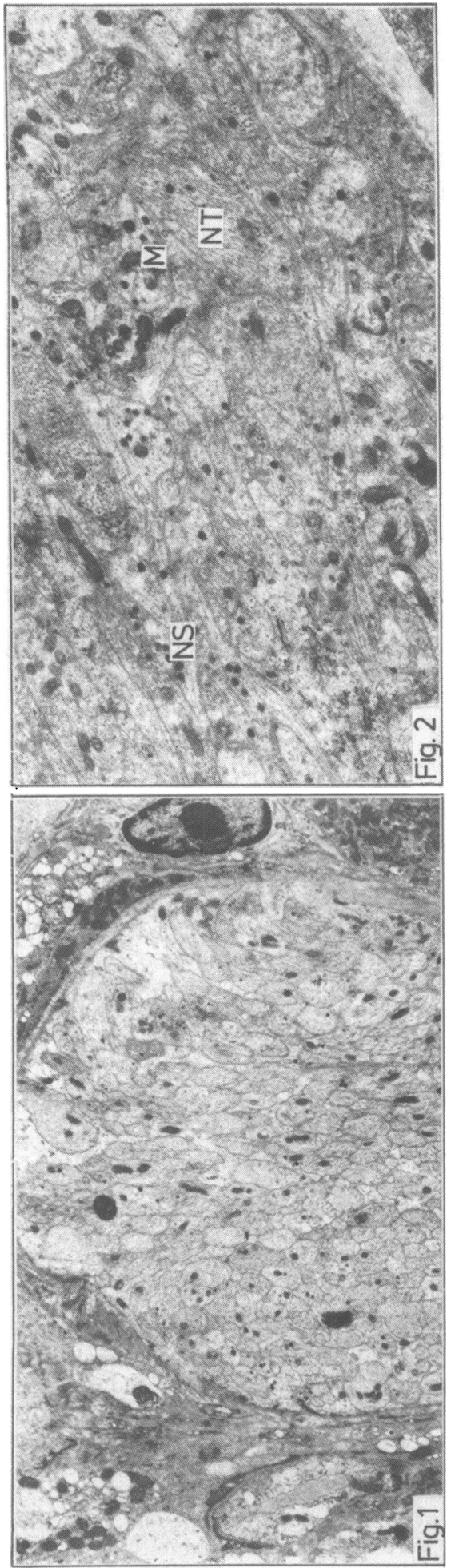
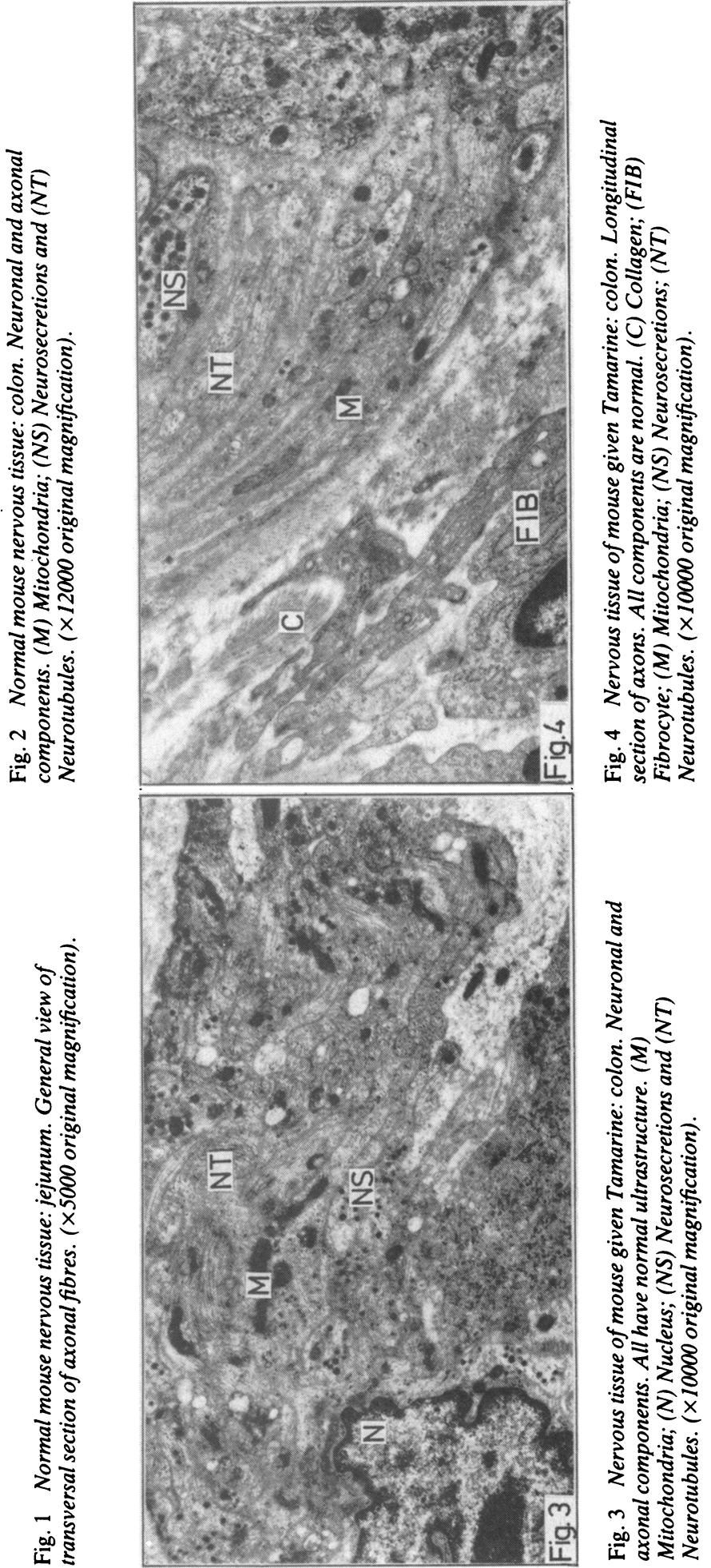
secretory activity. The Paneth cells in the jejunum were comparable with those of the control group. The presence of mitoses showed the regularity of the cell renewal cycle. No differences in the ultrastructure of jejunum and colon were detected between control animals and those receiving sennosides (group II). No sign of ultrastructural lesions of the nerve tissues were observed. The neurotubules and neurofilaments were abundant in the axons and the overall cell was perfectly normal (Figs. 3, 4, 5).

In the group treated with 1-8 dihydroxyanthraquinone (group III), a number of changes occurred in the nerve tissue, mainly in the form of vacuolisation of the axons and formation of lysosomal structures (Figs. 6, 7, 8, 9). The nature, extent and intensity of the lesions varied from very minor abnormalities to the appearance of fibrillar degeneration. The latter was rare, but all animals given 1-8 dihydroxyanthraquinone had neuronal damage and $40 \%$ of them exhibited severe neuronal changes. These changes occurred with a similar frequency and severity in the small intestine and in the colon.

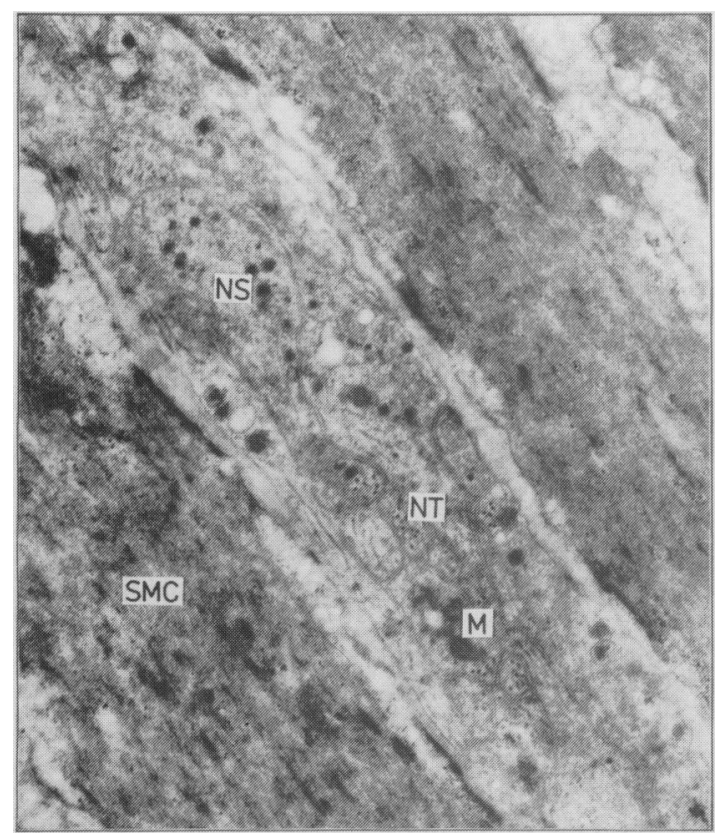

Fig. 5 Nervous tissue of a mouse given Tamarine: colon. Details of nerve components. (M) Mitochondria; (NS) Neurosecretions; (NT) Neurotubles; (SMC) Smooth muscle cell. $(\times 27000$ original magnification $)$.

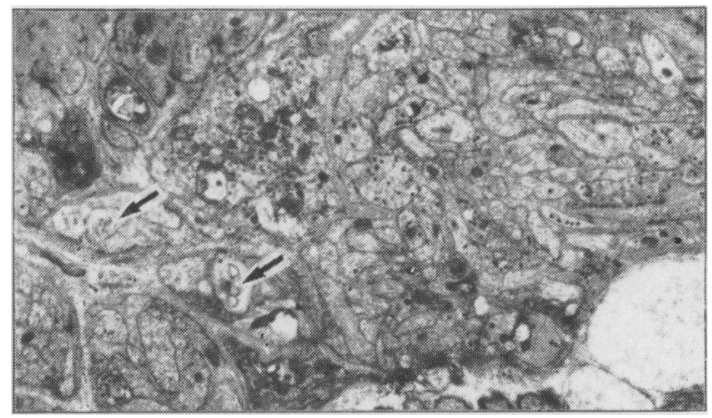

Fig. 6 Nervous tissue of mouse given 1-8 dihydroxyanthraquinone showing minor lysosomal abnormalities (arrows). ( $\times 6500$ original magnification). (Colon).

\section{Discussion}

Using EM examination to study the effects of anthraquinone laxatives on the ultrastructure of the intestinal tissue of the mouse, we found abnormalities of the intrinsic nerve tissue after treatment with 1-8 dihydroxyanthraquinone, the changes being evident not only in the colonic but also in the jejunal mucosa. It was difficult to judge if the lesions were focal or diffuse. It must be pointed out that during the first four weeks of the study, no diarrhoea was observed in the treated animals. The doses used in this experiment are those we usually use to study anthraquinone laxative activity in the mouse. ${ }^{14}$ The neuronal damage observed after treatment with 1-8 dihydroxyanthraquinone seems to occur after long

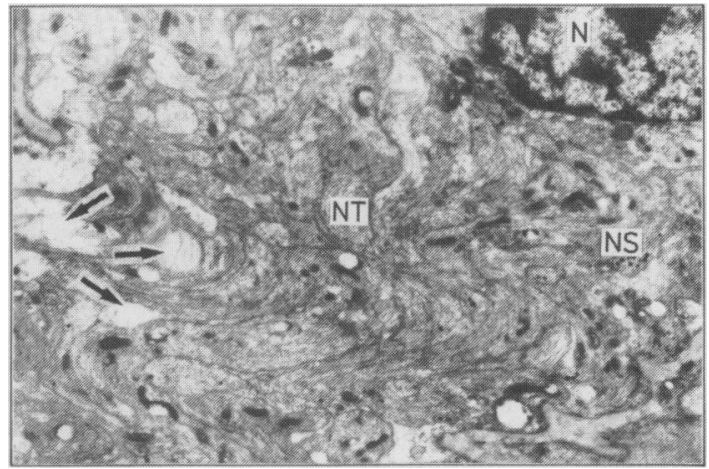

Fig. 7 Nervous tissue of mouse given 1-8 dihydroxyanthraquinone showing extended alterations with axonal vacuolisation (arrows). (N) Nucleus; (NS) Neurosecretions; $(N T)$ Neurotubules. $(\times 9000$ original magnification). (Jejunum). 


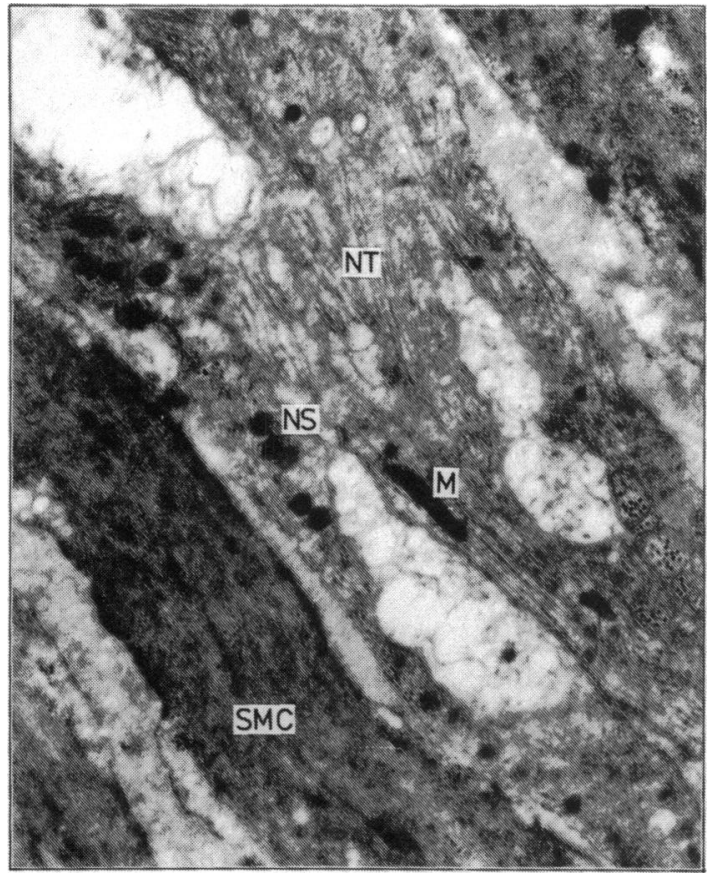

Fig. 8 Nervous tissue of mouse given 1-8 dihydroxyanthraquinone showing important axonal vacuolisation. (M) Mitochondria; (NS) Neurosecretions; (NT) Neurotubules; (SMC) Smooth muscle cell. $(\times 27000$ original magnification). (Colon).

term treatment at pharmacological doses. Damage of the jejunal and colonic nerves without any changes in other structures suggest that the initial action of free anthraquinones may be neuronal stimulation, perhaps leading to increased intestinal motility.

This conclusion differs from the generally accepted theories concerning the mechanism of laxative action. Many investigators no longer consider effects on propulsive activity as a primary mechanism, but rather as secondary consequences of altered electrolyte transport with fluid accumulation in the intestine. ${ }^{15-21}$ All the experiments concerned with water and electrolytes transport, however, have been conducted in vitro, or in situ, using very high concentrations of anthraquinone laxatives. It remains to be established that the alteration of fluid transport is the primary effect after oral administration at pharmacological doses. If neuronal stimulation is also the primary effect of anthraquinone laxatives in man and if the same lesions are likely to occur in man after prolonged treatment with usual doses of 1-8 dihydroxyanthra-

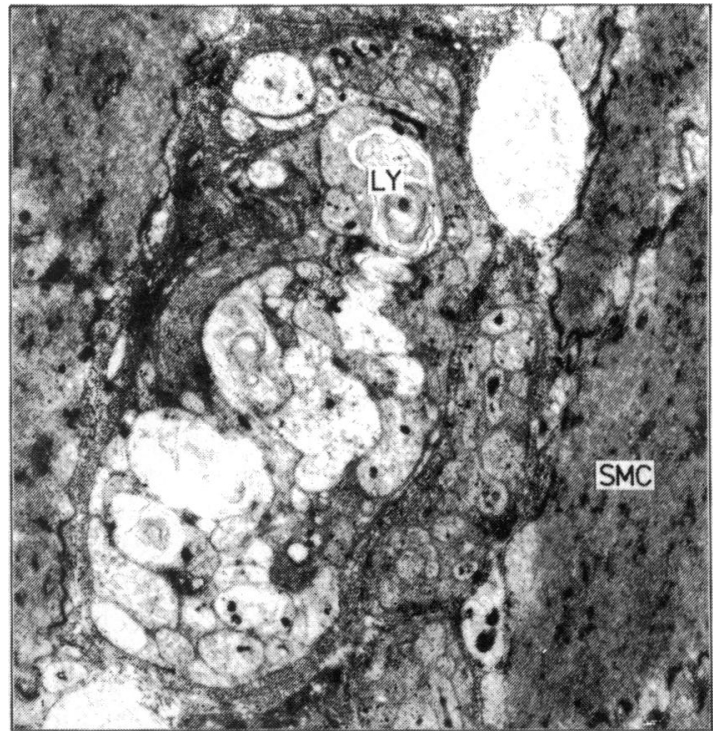

Fig. 9 Nervous tissue of mouse given 1-8 dihydroxyanthraquinone showing axonal degeneration (large vacuolisation, lysosomal structure). (LY) Lysosome; (SMC) Smooth muscle cell. ( $\times 6500$ original magnification). (Colon).

quinone, this could explain why patients become resistant to laxatives and need to increase the dose. Damage of myenteric neurones may affect the coordinated propulsive activity of the intestine producing a delay in transit of the intestinal contents so that the laxative efficacy of the drug is decreased: patients are then tempted to use larger doses. This is likely to produce severe electrolyte disturbances, such as increased net secretion in the small intestine and decreased absorption in the colon. Unfortunately, faecal output was not measured during the 16 weeks of the study so that it is not possible to state whether laxative efficacy decreased with time in the 1-8 dihydroxyanthraquinone treated animals.

Although the doses of sennosides and 1-8 dihydroxyanthraquinone used in this study were equipotent in terms of laxative activity in the experimental animals, no damage to the intestinal nerve tissue was observed after treatment with sennosides. Tested by Lou and Fairbairn method, ${ }^{22}$ as modified by Brittain and d'Arcy, ${ }^{23}$ laxative activity of sennosides is 24 -fold higher than that of 
1-8 dihydroxyanthraquinone. That ratio is of the same order as the ratio of doses therapeutically used in man. The relative low potency of 1-8 dihydroxyanthraquinone has been pointed out by other authors. $^{6810}$ Two important aspects of sennoside chemistry make them potentially less toxic than 1-8 dihydroxyanthraquinone. Firstly, their glycoside structure prevents absorption in the small intestine so that the doses needed to produce laxative activity are smaller than those of 1-8 dihydroxyanthraquinone. Secondly, they have as glycosides, no effect on water and electrolyte transport. ${ }^{16}$ They can only act at the colonic level where they have to be hydrolysed by bacterial enzymes to exert their laxative activity. Sennosides therefore, are unlikely to exhibit any pharmacological, or toxic effect on the small intestine either topically or systemically.

These considerations, together with our results on intestinal mucosa of mouse, suggest that at equivalent laxative activity, the doses needed to produce any intestinal cell toxicity should be much higher for sennosides than for 1-8 dihydroxyanthraquinone.

\section{References}

1 Smith B. Effect of irritant purgatives on the myenteric plexus in man and in the mouse. Gut 1968; 9: 139-43.

2 Riemann JF, Schenk J, Ehler R, Schmidt H, Koch H. Ultrastructural changes of colonic mucosa in patients with chronic laxative misuse. Acta HepatoGastroenterol 1978; 25: 213-8.

3 Dufour P, Gendre P, Meunier JM, Canellas J. Tolerance of mouse intestinal mucosa to a chronic ingestion of senna powder. Ann Pharm Fr 1983; 41: 571-8.

4 Lemli J. Stabilité des dérivés anthraquinoniques dans les préparations galéniques. Pharmaceut Tijdsch Belg 1963; 9-10; 149-54.

5 Fairbairn JW, Saleh MRI. Vegetable purgatives containing anthracene derivatives. Part VI: the instability of liquid preparations of senna during storage. J Pharm Pharmacol 1953; 5: 317-26.

6 Breimer DD, Baars AJ. Pharmacokinetics and metabolism of anthraquinone laxatives. Pharmacology 1976; 14 suppl 1: 30-47.

7 Van Os FHL. Natural anthraquinone laxatives: old drugs for modern use. Pharmacy Int March 1981; 68-70.
8 Thompson WG. Laxatives: clinical pharmacology and rational use. Drugs 1980; 19: 49-58.

9 Sasaki K, Yamauchi K, Kuwano S. Metabolic activation of sennoside A in mice. Planta Med 1979; 37: 370-8.

10 Fairbairn JW, Moss MJR. The relative purgative activity of 1-8 dihydroxyanthracene derivatives. $J$ Pharm Pharmacol 1970; 22: 584-93.

11 Lemmens $\mathrm{L}$. The laxative action of anthracene derivatives. 2. Absorption, metabolism and excretion of sennoside A and B in the rat. Pharmaceut Weekbl Sci Edinb 1974; 1: 178-85.

12 Ewe K. The physiological basis of laxative action. Pharmacology 1980; 20 suppl 1: 2-20.

13 Smith B. Pathology of cathartic colon. Proc $R$ Soc Med 1972; 65: 288.

14 Dufour P. Comparison of laxative activity of sennosides and Danthron. Bull Soc Pharm Bordeaux. (In press).

15 Lemmens L. De laxarende werking von antrachinonderivaten. I. De invloed van de antraceenderivaten, aanwezig in sennae folium en sennae fructus, op de water-en elektrolytbeweging in het colon von de rat. Pharmaceut Weekbl Sci Edinb 1976; 111: 113-8.

16 Lemmens L Borja $E$. The influence of dihydroxyanthracene derivatives on water and electrolyte movement in rat colon. J Pharm Pharmacol 1976; 28: 498-501.

17 Goerg KJ, Wanitschke R, Schultz L. Scanning electron microscopy study of the effect of rhein of the surface morphology of the rat colonic mucosa. Pharmacology 1980; 20: suppl 1: 36-42.

18 Forth W, Rummel W, Baldauf J. Wasser und elektrolytbewegungen am dünn - und dickdarm unter dem einfluB von laxantien, ein beitrag zur klärung ihres wirkungsmechanismus. Naunyn Schmiedebergs Arch Pharmacol 1966; 254: 18.

19 Rask-Madsen J, Brix-Jensen P. Electrolyte transport capacity and electrical potentials of the normal and the inflamed human rectum in vivo. Scand J Gastroenterol 1973; 8: 169 .

20 Rask-Madsen J. Transepithelial ionic transport and electrical polarization in the large bowel. Scand $J$ Gastroenterol 1974; 9: 223.

21 Flingl E. Antidiarrheal agents and laxatives: changing concepts. Clin Gastroenterol 1979; 8: (1).

22 Lou TC, Fairbairn JW. The biological assay of vegetable purgatives. J Pharm Pharmacol 1951; 3: 225-32.

23 Brittain RT, d'Arcy PF, Grimshaw JJ. Observations on the use of a mouse bioassay method for investigating purgative activity. J Pharm Pharmacol 1972; 14: 715-21. 